\title{
On-road Performance Analysis of Tallow Biodiesel on a 2.8 Toyota Raider Hilux
}

\section{Clever Ketlogetswe ${ }^{1}$, Jerekias Gandure ${ }^{1}$, Mbako Jonas $^{1}$}

\author{
${ }^{1}$ Department of Mechanical Engineering, University of Botswana, P/Bag UB0061, Gaborone, Botswana
}

\begin{abstract}
Biodiesel has generated increased interest globally as an alternative to petroleum diesel. Biodiesel burns more completely than petroleum diesel due to its high oxygen content, producing lower emissions of hydrocarbons, carbon monoxide and particulate matter. Biodiesel may however produce high or low nitrogen oxide and carbon dioxide emissions, depending on feedstock, engine type and test conditions. The current study therefore sought to analyse emissions from biodiesel blend of 10\% (B10) synthesized from tallow, on an on-road setting using an emissions gas analyser on 2.8 Toyota Raider Hilux. The results showed significantly lower emissions of HC and CO with increase in speed, while $\mathrm{NO}_{\mathrm{x}}$ emission levels demonstrated a linear relationship with increase in vehicle speed. The trends are attributed to road landscape and surface conditions. The results from the current tests are specific to the 2.8 Toyota Raider Hilux tested, and cannot be generalized to other vehicles.
\end{abstract}

Keywords: Tallow Biodiesel, On-Road Performance, Emissions, Road Landscape, Road Surface

\subsection{Introduction}

The environmental pressure from international organisations such as the International Penal on Climate Change (IPCC) and the United National Environmental Programmes (UNEP) to reduce levels of greenhouse gas emissions from energy sector particularly transport sector have stimulated rapid development of biofuels world over. Several authors including Mitchell (2011), Bechman (2015a) and Davappa et al (2010) have reported that globally, Brazil, United States of America and European Union are the three largest players in biofuels markets. For example, between 2001 to 2010, the United States of America recorded an increase of biofuel production from 6.7 billion litres to over 55.38 billion litres, thus approximately $87.9 \%$ increase over 9 years (Beckman 2015a). This growth in production and use of biofuels particularly among the major players is expected to continue increasing in future as these countries have set relatively high targets of biofuel consumption in their energy mix. Furthermore, the European Union Directive 2009/28/EC article 3(4) calls for its member states to ensure that the share of energy from renewable sources in all forms of transport by 2020 is at least $10 \%$ of the final consumption of energy in transport sector. The directive further states that the blending of biofuels is one of the methods available for member states to meet the proposed target.

Although, from the above, it is clear that Brazil, USA and the European Union are the three major players in the biofuel markets, a study by Adrian and
Thomson (2009) concluded that Asian region could potentially become a major market and exporter of biofuels mainly because of relatively huge quantity of feedstock such as Palm oil which is used for biodiesel production in most of the countries in the Asian region. These countries include Indonesia, Malaysia, Thailand, the Philippines and India. The authors further noted that rapid development of biofuels is driven by conducive biofuel policies issued by individual governments in the region. The observation is further reinforced by a study by Achten et al (2010) which reported that in 2009 the government of India approved its national policy on biofuel's targeting a 20\% (B20) blend of biofuel with gasoline and diesel by the end of 2017.

In the African continent the development of biofuels is relatively low. Several authors including Amigun et al (2011) blame lack of biofuel policies, strategies and informative research activities by public universities and research centres to stimulate formulation of appropriate biofuel policies in most African states. The authors further echoed that many of the policies in most African states are being recommended and developed by global commercial interest rather than national or regional government, resulting in many differing and contradicting frameworks and policies. All these hinder the market development of biofuel industry in African continent. Despite the above observations, the Southern African Development Community Technical Report (2012) projected liquid biofuel targets and land requirements for the plantation of energy plants for the region

This article is published under the terms of the Creative Commons Attribution License 4.0

Author(s) retain the copyright of this article. Publication rights with Alkhaer Publications.

Published at: http://www.ijsciences.com/pub/issue/2018-02/

DOI: 10.18483/ijSci.1541; Online ISSN: 2305-3925; Print ISSN: 2410-4477 
between 2020 and 2030. Figure 1 demonstrates, among others, biodiesel and bioethanol market demand by SADC member states projected in a situation where blending ratios of B5 and B10 are considered and implemented for the years 2020 and 2030 respectively. The same figure further demonstrates land required for the cultivation of Jatropha and sugar cane for biodiesel and bioethanol production respectively.

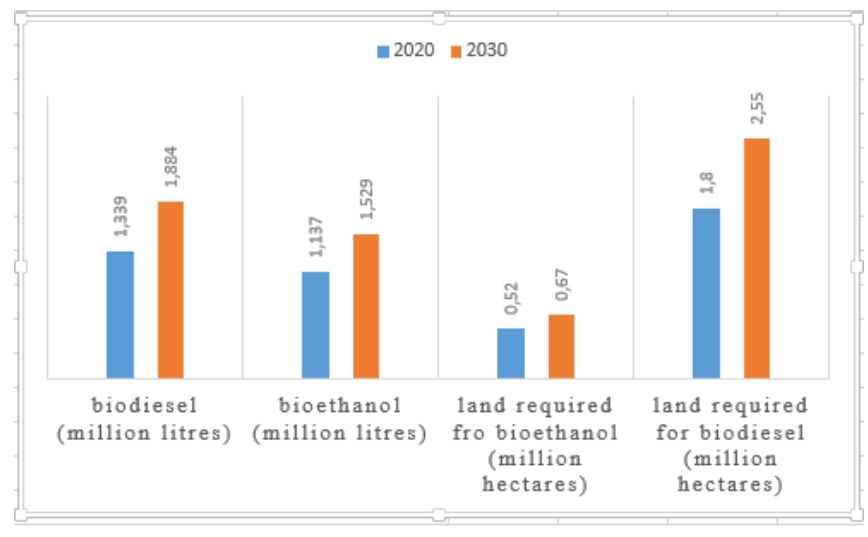

Figure 1: Projected selected biofuel required by SADC

Member's states (Based on SADC Renewable Energy Strategy and Action 2012-2030 Technical report May 2012.)

Botswana, a member of the Southern African Development Community (SADC), is expected to contribute towards the set targets. However, the country is among those which are still developing biofuel policies and implementation strategies to ensure political commitment and possible long-term integration of biofuels into the overall national development plans. The country's draft national energy policy is still to be approved by the government. The draft policy have general policy statements on liquid biofuel development such as section 6.11 (d) which states that the government will provide incentives to encourage tertiary institutions to develop research programmes for the application and implementation of renewable energy technologies including biodiesel. However it should be noted that although there is no biofuel policy in Botswana, there is an indication that political commitment to develop biofuels industry in the country is high. For example, in 2012 the government of Botswana through an international strategic partnership with the Japanese International Corporation Agency (JICA) engaged in a five year scientific research project on development of Jatropha species adapted to Botswana's climatic conditions. The study was completed in April 2017. The results of the research are expected to stimulate the development of the country's first biofuel policy and implementation strategies. This paper reports onroad test results obtained from 2.8 DVA double-cab diesel vehicle powered with B10 (10\% biodiesel blend) under different driving conditions. The results of the present investigation are expected to contribute to the development of liquid biofuel policy document by policymakers in Botswana and stimulate rapid development of small scale biofuel industry in the country. The development of small scale biofuel industry in the country should be seen as offering immense potential to contribute to poverty alleviation among rural population in the country.

\subsection{Research Equipment and Fuels}

A 2.8 Toyota Raider Hilux powered by 2 GD-FTV 4 cylinder in line, 4 cycle diesel engine with turbocharger was used to perform systematic experimental investigations (on road tests). The engine has a bore and stroke of 92 by $90 \mathrm{~mm}$, and a displacement of $2393 \mathrm{~cm}^{3}$. The vehicle is equipped with 6 - speed manual transmission. Emission analyser model $800 \mathrm{HP}$ equipped with automatic data recording was employed for data collection. The analyser is designed to test the vehicle emissions on the road. It is powered by a $110 / 220 \mathrm{~V}$ AC/DC converter or $12 \mathrm{~V} \mathrm{DC}$. The system was linked to a PC through wireless interface. The analyser is capable of recording five gases namely $\mathrm{HC}, \mathrm{CO}_{2}, \mathrm{NO}_{\mathrm{x}}, \mathrm{CO}$ and $\mathrm{O}_{2}$.

The biodiesel was prepared from beef tallow by transesterification processes. A heating mantle was prepared while the beef fat was allowed to cool from $110^{\circ} \mathrm{C}$ to approximately $60^{\circ} \mathrm{C}$ before being transferred into a $5 \mathrm{~L}$ three neck round bottom flask (reactor). Potassium hydroxide $(\mathrm{KOH})$ to the amount of $25 \mathrm{~g}$ was dissolved in $1.6 \mathrm{~L}$ methanol. An amount of approximately $2 \mathrm{~L}$ of beef fat was then mixed with the solution of methanol and potassium hydroxide within the flask at a ratio of 5:4 (oil to $\mathrm{MeKOH}$ ). The flask was then placed on a heating mantle with the mechanical stirrer and thermocouple introduced in, along with a condenser for methanol recovery. The reaction temperature was then maintained at approximately $60^{\circ} \mathrm{C}$, with the mechanical stirrer revolving at approximately $230 \mathrm{rpm}$. The reaction was allowed for an hour to ensure a complete reaction, and then the mixture was transferred to a separator and allowed to settle for approximately 24 hours to ensure a complete separation of glycerol from a mixture of methyl esters and residual methanol. A rotary vacuum evaporator (Buchi R114) was then used to recover unreacted methanol from the biodiesel.

Prior to blending processes, a chemical composition of the biodiesel was performed in order to ensure compliancy with major international biodiesel standards such as European standards (EN 14103).

\subsection{Experimental Procedure}

Biodiesel fuel produced from beef tallow was blended with 50PPM petroleum diesel to produce 
B10. The fuel (B10) was then used to run the vehicle under review. The on road tests were performed on a highway (A1 road) from Gaborone City towards Francistown City. The emission sensor from the emission analyser was inserted into the exhaust tail pipe while the other hardware and the $\mathrm{PC}$ which was linked to the analyser were located in the back seat of the vehicle. When the engine had reached its operating conditions, the vehicle was locked to a specific engine speed for $20 \mathrm{~km}$ for the engine to reach steady state conditions before recording of the exhaust emissions could commence. Recording process was then performed at an interval of five (5) minutes until ten (10) readings were recorded. The processes were repeated for different vehicle speeds namely; $40 \mathrm{~km}, 60 \mathrm{~km}, 80 \mathrm{~km}, 100 \mathrm{~km}$ and $120 \mathrm{~km}$ which is the maximum permissible speed limit in Botswana. For each speed exhaust tail emission levels were recorded and an average value calculated. The average value for all the five exhaust tail emissions for each driving vehicle speeds were again used as input values in drivability and emission calculation software (version 2) to further calculate combustion efficiency, oxygen dilution value, and lambda $(\boldsymbol{\lambda})$. For simplicity, only a sample of results obtained from on-road tests have been presented and discussed in Section 3.0. This enables the main findings of the study to be identified and explained.

\subsection{Presentation and discussions of results}

The selected results obtained during on-road test are presented and discussed in this section. As mentioned earlier in section 1.0, the main objective of the investigation was to determine vehicle performance in terms of emission levels of $\mathrm{NO}_{\mathrm{x}}, \mathrm{HC}, \mathrm{CO}_{2}, \mathrm{CO}$ and $\mathrm{O}_{2}$ when the vehicle under review was fuelled with $\mathrm{B} 10$. The biodiesel was produced from beef tallow as mentioned earlier. The authors, note that in practice the levels of oxygen and carbon dioxide can be used as indicators to the performance of a combustion processes. Although much experimental work has been done on the blending of biodiesel and petro diesel, there has been limited on on-road tests to validate the effects of driving and road conditions on the vehicle performance particularly the emission levels. The present study offered the opportunity. The data used in the present investigations are average values calculated from data collected over time periods of 30 minutes driving time for each selected vehicle speed. Figure 1 shows $\mathrm{NO}_{\mathrm{x}}$ and lambda (combustion air ratio) profiles as the vehicle speed was increased from 40 to $120 \mathrm{~km} / \mathrm{h}$ along the Gaborone - Francistown (A1 road).

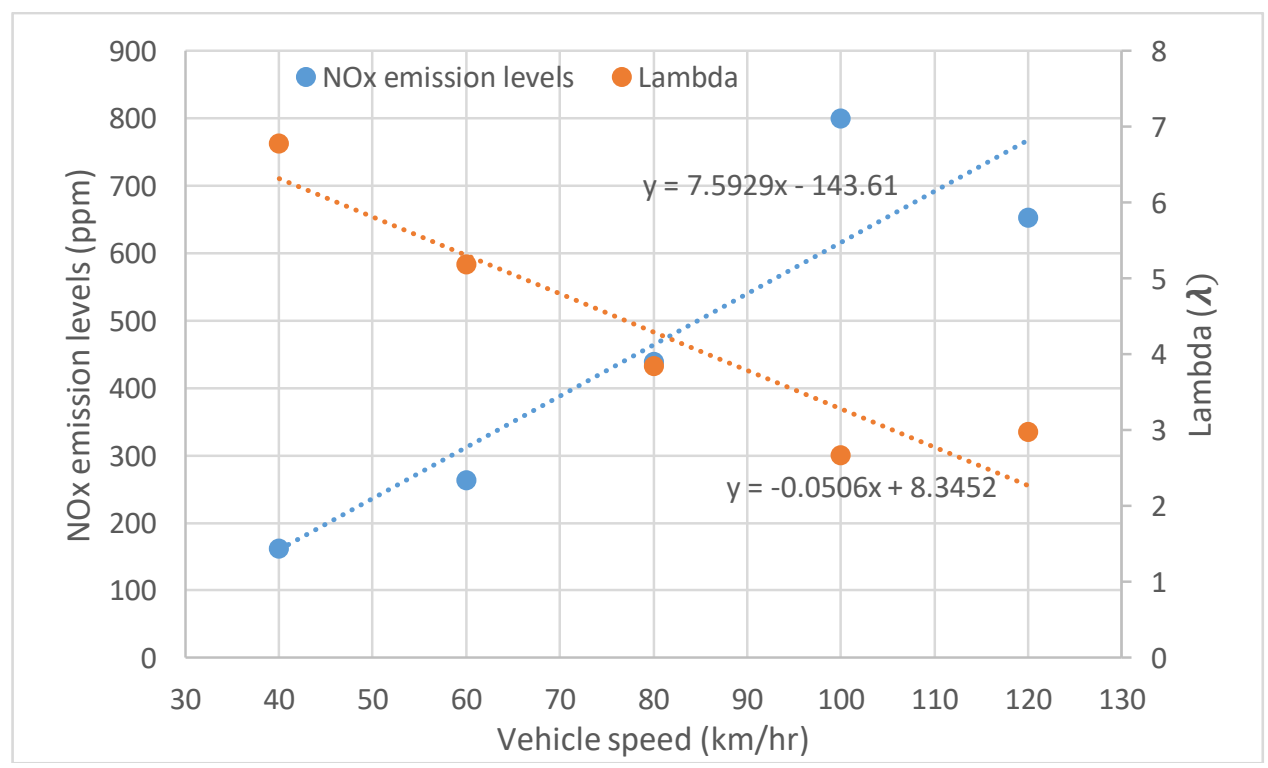

Figure 1: Relationship between $\mathrm{NO}_{\mathrm{x}}$ and lambda $(\boldsymbol{\lambda})$ as vehicle speed increases.

As expected increasing vehicle speed decreased combustion air ratio (lambda) and increased $\mathrm{NO}_{\mathrm{x}}$ emission levels. NOx emission levels is reported by several authors including Wail M. Adaileh and Khaled. S. AlQdah (2012) to be increased with the proportion of biodiesel in the blends. It is also influenced by peak pressure, and combustion temperature, thus (thermal $\mathrm{NO}_{\mathrm{x}}$ which is strongly influenced by the oxygen concentration levels). The authors believe that the above factors are the major contributors to the steady increase in NOx emission levels as demonstrated by figure 1 . The equation for NOx emission levels suggest that the type of the vehicle under review running on B10 along the A1 road produced approximately $7.59 \mathrm{ppm}$ of NOx per unit speed increment $(\mathrm{km} / \mathrm{h})$ in vehicle speed. The results, also show that lambda $(\boldsymbol{\lambda})$ decrease with increase in vehicle speed. It is pertinent to mention here that according to the vehicle manufacture specifications, the maximum vehicle speed is 
$172 \mathrm{~km} / \mathrm{h}$. However, this speed is specified for selected countries including Saudi Arabia, Sultanate of Oman, Bahrain, United Arab Emirates, Qatar and Kuwait. The data for $\boldsymbol{\lambda}$ suggest that the optimal maximum vehicle speed along A1 road for the test under review is the maximum allowable speed in the country of $120 \mathrm{~km} / \mathrm{h}$. For example, the results in figure 1 suggest that at vehicle speed of 130 and $140 \mathrm{~km} / \mathrm{h}$, the values for $\lambda$ are 1.767 and 1.261 respectively, beyond which the $\lambda$ value drops below unit making the vehicle to operate on rich mixture. Available information indicate that a leaner mixture than lambda 1.7 may not combust reliably and cause misfiring which raise $\mathrm{HC}$ emissions. As such the results revealed that at the maximum allowable speed limit in Botswana of $120 \mathrm{~km} / \mathrm{h}$ the $\boldsymbol{\lambda}$ value is approximately 2.27 which is approximately $25 \%$ above the threshold of 1.7. Based on these observations, it is approximate to conclude that powering diesel engines particularly the one under review with B10 should be seen as offering immense potential for biodiesel development in Botswana. The results in figure 2 depict emission levels of $\mathrm{HC}$ with respect to vehicle speed.

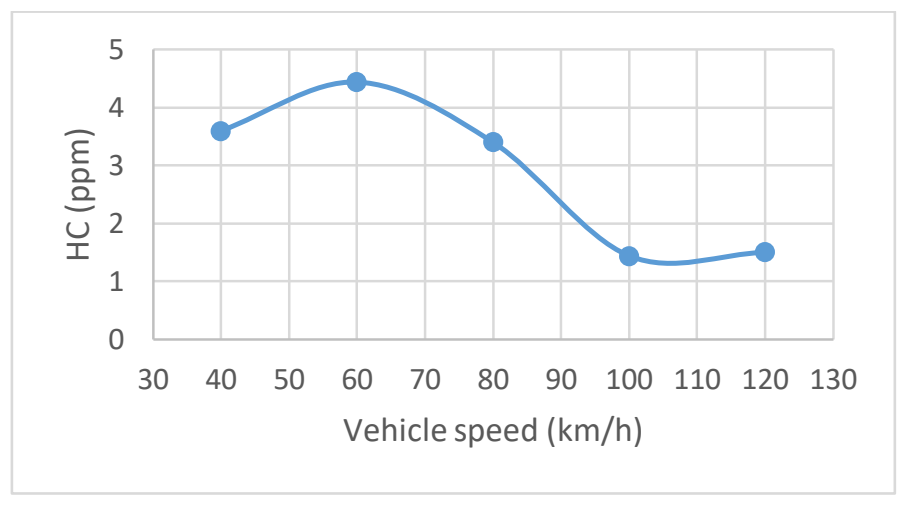

Figure 2: Variation of $\mathrm{HC}$ with respect to vehicle speed

It should be explained here that at vehicle speed of $40 \mathrm{~km} / \mathrm{h}$ the vehicle could not be engaged to its top driving gear. The vehicle was driven on low gear (third gear). Considering the results in figure 2 and the results obtained by several researchers who looked into engine performance using different blending ratios in laboratory environment, the results in figure 2 are pointing to a different direction. Firstly, the concentration of $\mathrm{HC}$ demonstrated by figure 2 are relatively low. Wail $M$. Adaileh and Khaled. S. AlQdah (2012) investigated performance of diesel engine fuelled by B10 and B5 produced from waste cocking oil in a laboratory environment and reported $\mathrm{HC}$ emission levels in the range 60 to $70 \mathrm{ppm}$. The results in figure 2 generally show decrease in $\mathrm{HC}$ emission levels with increase in vehicle speed. The relatively low concentration of $\mathrm{HC}$ as demonstrated by figure 2 appears to point in a positive direction. The data in figure 3 should be viewed parallel with figure 4 and 5 , which show variation in emission levels of $\mathrm{CO}_{2}$ and $\mathrm{CO}$ with respect to increase in vehicle speed.

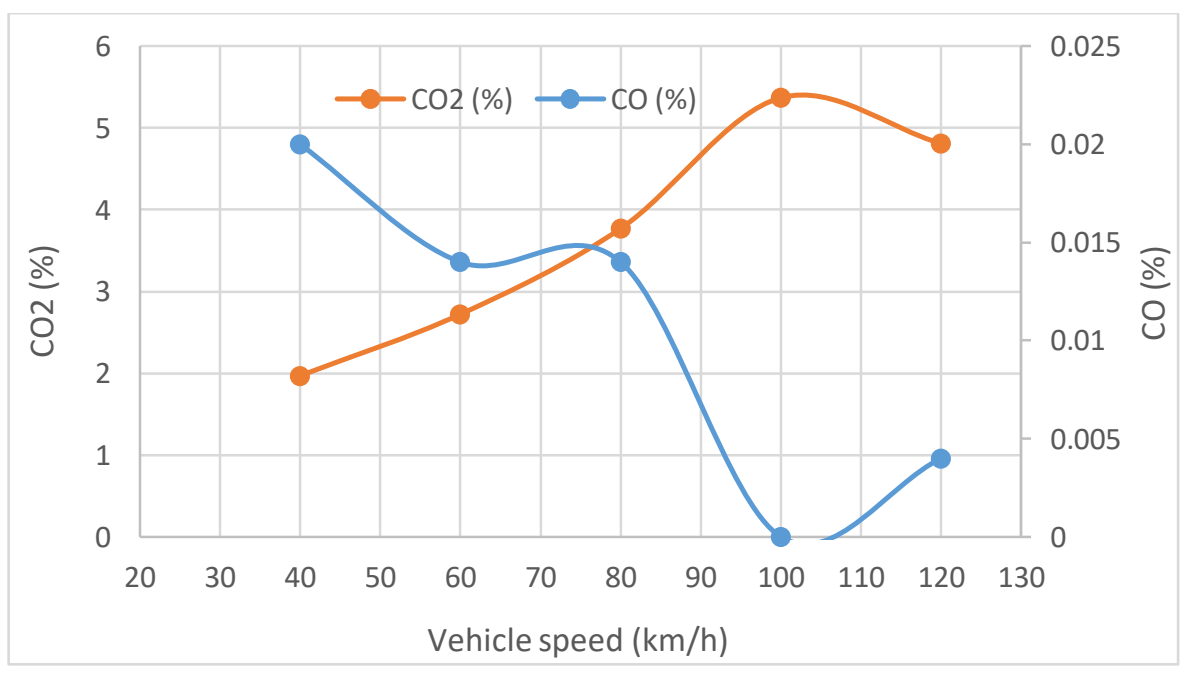

Figure 3: variation of $\mathrm{CO}_{2}, \mathrm{CO}$ with respect to vehicle speed

The results presented in figure 3 show that the $\mathrm{CO}$ concentration levels decrease with increase in vehicle speed, while the $\mathrm{CO}_{2}$ show an increase with increase in speed. The peak $\mathrm{CO}_{2}$ emission level which 
corresponded to the lowest recorded $\mathrm{CO}$ emission level occurred at the vehicle speed of $100 \mathrm{~km} / \mathrm{h}$. This could be explained by the results in figure 4 which demonstrate that the minimum oxygen concentration level of $13.42 \%$ in the exhaust tail was recorded at vehicle speed of $100 \mathrm{~km} / \mathrm{h}$.

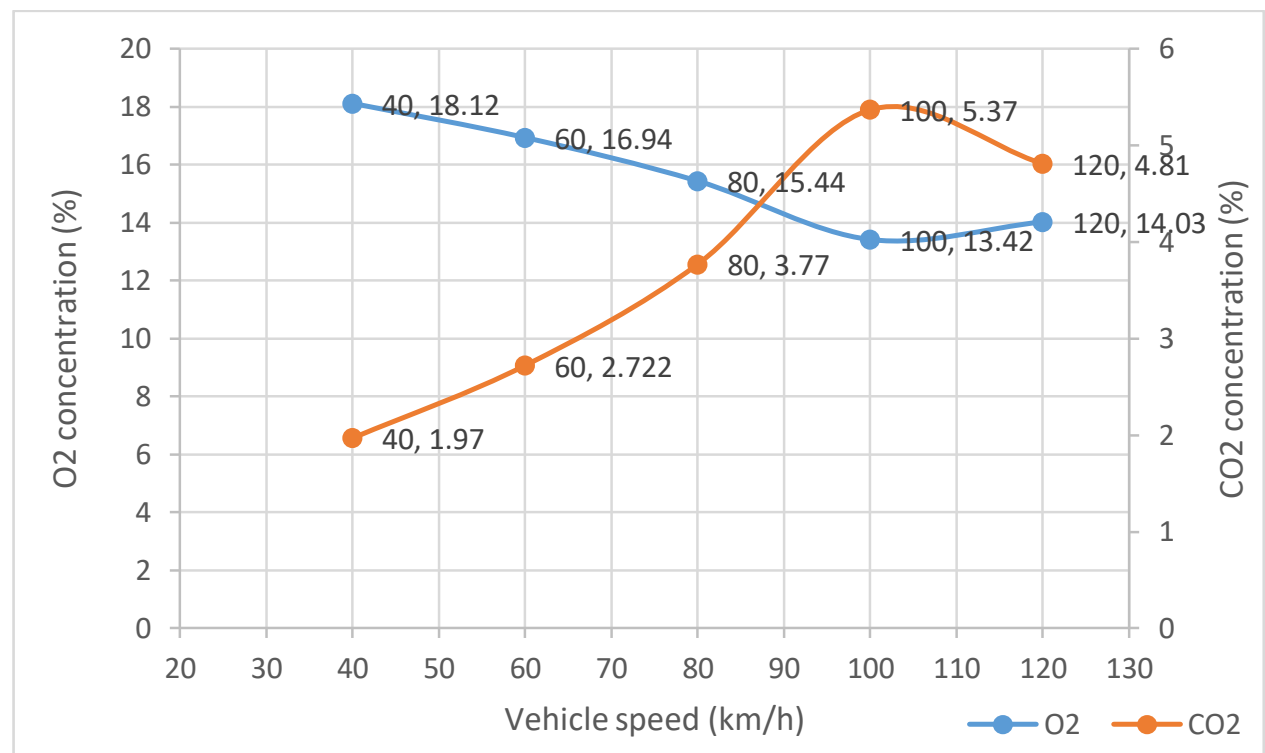

Figure 4: variation of $\mathrm{CO} 2, \mathrm{O} 2$ with respect to vehicle speed

The results in figure 3 and 4 suggest that the optimum condition for the vehicle under review is when the oxygen concentration level in the flue gases is approximately $13.42 \%$. Figure 5 shows variation of oxygen concentration levels for the different vehicle speeds and reveals that the lowest readings were recorded at vehicle speed of $100 \mathrm{~km} / \mathrm{h}$, with the standard deviation of 0.38 .

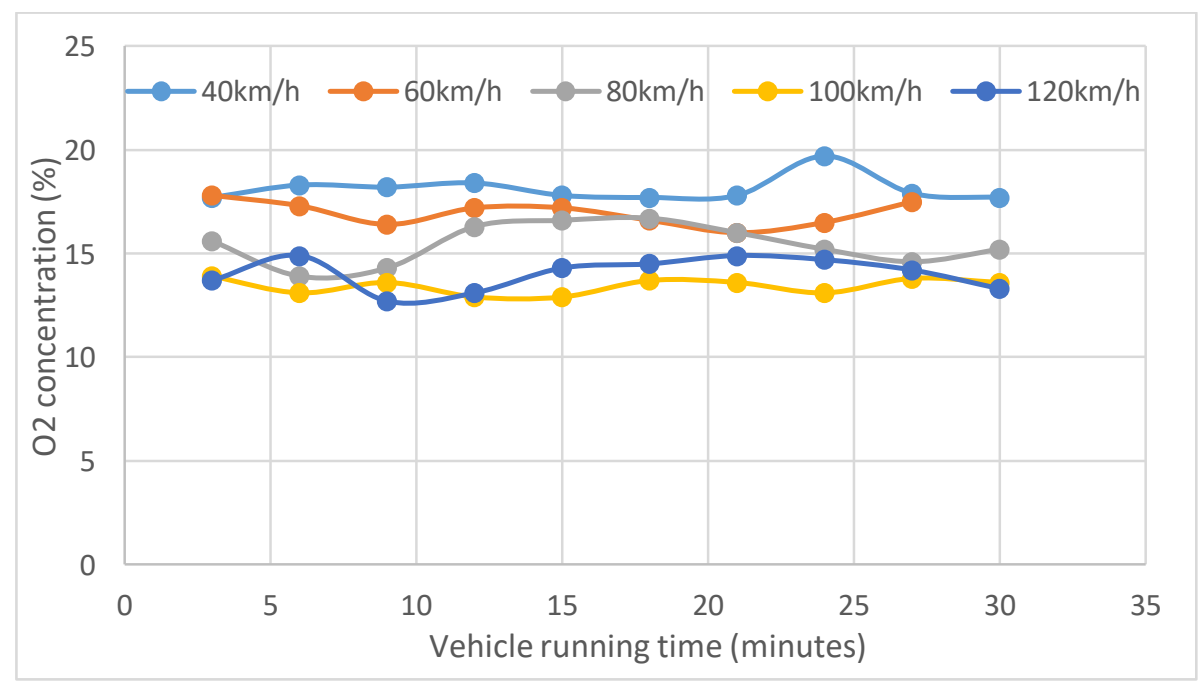

Figure 5: variation of oxygen concentration with respect to vehicle running time

It should also be reported here that the maximum standard deviation of 0.972 was recorded for vehicle speed of $80 \mathrm{~km} / \mathrm{h}$. It is appropriate to conclude that relatively high oxygen concentration levels at relatively low vehicle speeds has a direct bearing on the overall emission profiles demonstrated in the present investigations.

\subsection{Conclusions}

Determination of emission profiles have been performed at different vehicle speeds and the following conclusions can be made:

a. Comparing the present results with results by other researchers who performed their investigations under laboratory conditions, the present investigations revealed that on-road results produced relatively low levels of hydrocarbons (HC) and CO. 
b. Increase in vehicle speed results in decrease in emission levels of $\mathrm{HC}$, and $\mathrm{CO}$, contrary to several reports under laboratory environment when the engine load is increased. The authors believe the difference could be due to a number of factors including the road landscape and the road surface conditions.

c. For optimum engine performance, oxygen concentration level in the flue gases should be $13.42 \%$ above which the level of $\mathrm{HC}$ and $\mathrm{CO}$ are relatively high.

d. The vehicle maximum speed along A1 road when the vehicle under review is fuelled with B10 is 140 (lambda 1.261), beyond which the vehicle will start to run on rich mixture resulting in high $\mathrm{HC}$.

e. The lambda value for maximum allowable speed limit in Botswana $(120 \mathrm{~km} / \mathrm{h})$ along the $\mathrm{A} 1 \mathrm{road}$ is 2.27 .

f. $\mathrm{NO}_{\mathrm{x}}$ emission levels demonstrated a linear relationship with increase in vehicle speed and is also influenced by the road landscape and road surface conditions.

g. Overall, the results are pointing to a positive direction and offers immense potential for significant reduction of emission levels on our roads.

\section{References}

1. Adrian Zhon and Elspeth Thomoson (2009). The development of biofuels in Asia. Applied Energy 86 (2009) $511-520$.
2. Bamikole Amigun, Josepline Kaviti Musango and William Stafford. Biofuels and sustainability in Africa. Renewable and Sustainable Energy Reviews 15 (2011) 1360 - 1372.

3. Beckman, J. (2015(a)) 'Biofuel Use in International Markets : The Importance of Trade', (144).

4. Devappa, R. K., Makkar, H. P. S. \& Becker, K., 2010 Jatropha Toxicity-A Review. Journal of Toxicology and Environmental Health, 13(6), p. $476-507$.

5. Directive 2009/28/EC of the European Parliament and of the Council of 23 April 2009 on the promotion of the use of energy from renewable energy sources and amending and subsequently repealing Directives 2001/77/EC and 2003/30/EC (OJ L 140, 5.6.2009, p. 16).

6. Draft Botswana National Energy Policy (March 2016). Ministry of Minerals, Energy and Water Resources.

7. Gandure, Ketlogetswe and Temu: Fuel properties of biodiese produced from selected plant kernel oils indigenous to Botswana. A comparative analysis. Renewable Energy; 2014, $68,414-420$.

8. Mitchell, D. (2011) Biofuels in Africa and Challenges. doi 10.1596/978-0-8213-8516-6.

9. SADC renewable energy strategy and action plan 2012 2030. Technical report $30^{\text {th }}$ May 2012.

10. The Republic of Botswana National Development Plan 11, April 2017 - March 2023. Ministry of Finance and Development Planning - June 2016.

11. The blue print Botswana Vision 2036 (2016): ISBN 97899912-75-57-6

12. Wail M. Adaileh and Khaled S. AlQdal: Performance of diesel engine fuelled by a biodiesel extracted from a waste cocking oil. Energy Procedia 18 (2012) 1317 - 1334

13. Wonter M.J Achten, Joana Almeida, Vincent Fobelets, Evelien Bolle, Erik Mathijs, Virendra P. Singh, Dina N. Tewari, Louis V. Verchot and Bart Muys. Life cycle assessment of Jatropha, biodiesel as transport fuel in rural India. Applied Energy 87 (2010) 3653 - 3660. 